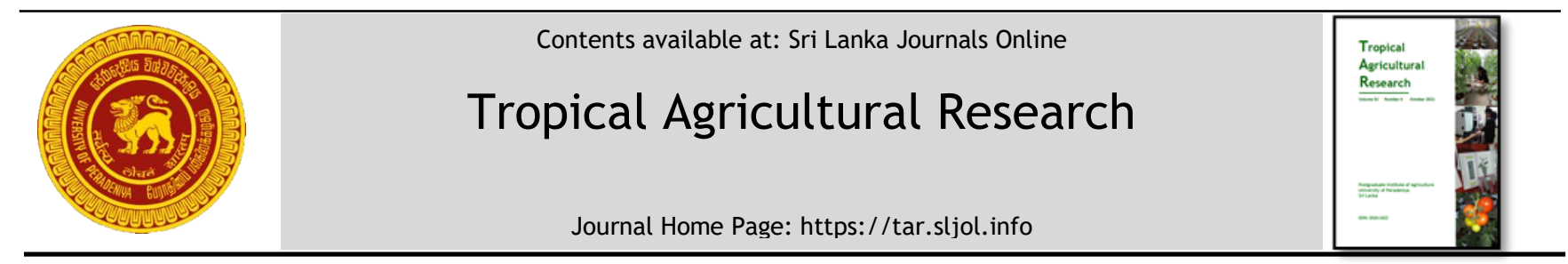

\title{
MODIFICATION OF POTATO STARCH BY EMERGING TECHNOLOGIES
}

\author{
Jhoseline S. Guillén ${ }^{1^{*}}$ \\ ${ }^{1}$ Food Technology Department, Faculty of Food Engineering, University of Campinas, Campinas, SP, Brazil.
}

\section{ARTICLE INFO}

\section{Article history:}

Received: 04 June 2020

Revised version received: 13 April 2021

Accepted: 23 August 2021

Available online: 01 October 2021

\section{Keywords:}

Chemical modification Emerging technologies

Functional properties

Potato starch

Rheological characteristics

\section{Citation:}

Guillén, J.S. (2021). Modification of potato starch by emerging technologies. Tropical Agricultural Research, 32(4): 480-487

DOI: http://doi.org/10.4038/tar.v32i4.8516

Guillén, J.S.

https://orcid.org/0000-0002-0899-6725

\section{ABSTRACT}

It is estimated that $56 \%$ of the annual production of potato starch in Europe is destined to the food industry while the remaining $44 \%$ is divided between chemical textile and paper industries. Native potato starch is subjected to modification processes that improve its functional properties such as gelatinization temperature, retrogradation time, resistance to viscosity loss and solubility, to be able to be used in different refrigerated and non-refrigerated food as stabilizing agents and thickeners. The use of chemical substances during chemical modification processes usually degrades some rheological characteristics of starch, in addition the process itself may be harmful to human health and the environment. On the other hand, physical modification using emerging technologies such as high hydrostatic pressure, microwave and ultrasound are shown as potential alternatives, since they offer some advantages such as higher productivity, performance, lower consumption of organic solvents, shorter processing time and it is more environmentally friendly by not generating hazardous industrial waste. The objective of this review is to provide updated information on the application of emerging technologies in potato starch and its potential to improve functional properties.

\footnotetext{
${ }^{*}$ Corresponding author: jhoselineguillen@gmail.com
} 


\section{INTRODUCTION}

Starch is a reserve polysaccharide produced in the chloroplasts of green leaves and amyloplasts of seeds, legumes and tubers; and it is important for humans for its great energy contribution for daily physical activities. The biosynthesis of potato starch is a complex process that requires the intervention of different enzymes, including ADPglucose pyrophosphorylase (AGPase), starch synthase (SS), starch branching enzyme (SBE) and starch de-branching enzyme (DBE), to accelerate the metabolic reactions of the plant, such as starch branching enzymes, and starch synthases. Starch granules vary according to the species and variety, however, most of them are between 39 and 71 microns, and have an oval shape (Raventós, 2005, Pérez and Bertoft, 2010; Dupuis and Liu, 2019).

Currently, the use of starch in food products has been increasing, mainly in reformulated products to improve technological characteristics or to reduce and / or remove some ingredients. In the food industry, starch can be used as a preservative for breads, thickener and stabilizer for fruit cakes, soups, desserts, and sauces; in the paper industry, as a binder since it increases the mechanical resistance of the paper, and in the textile industry, starch is used as a textile sizing agent (De León, 2015; Nurulain et al., 2018) However, native starches do not always adapt to the different processes that the industry applies to products, due to its low shear resistance, low thermal decomposition, high level of retrogradation and syneresis (Bello-Pérez et al., 2002). Modified starches are an alternative to replace native starches in the food industry, since they allow increasing resistance to retrogradation related to the shelf life of the product, optimize the water retention capacity, conditioning the organoleptic characteristics of the product, and stabilize the syneresis process, avoiding intensive changes in the structure of the products that require firmness during the freeze-thaw process. (Ramos et al., 2018).

The native starch subjected to chemical modification, changes some of its functional properties such as gelatinization temperature, retrogradation time, resistance to viscosity loss and solubility (Goel et al., 2020). However, chemical modification represents a disadvantage in the rheological properties of starch, and also generates toxicity for humans and the environment (Mollega et al., 2011). The development of new products implies that the techniques used for the modification of starches are constantly evolving, so it is necessary to investigate new techniques that meet the demands of the consumer to obtain a product with the desired characteristics and that are friendly to the environment (Schmiele et al., 2019). In this context, the emerging technology of potato starch modification is promising for process optimization, the development of new products with minimal effects on organoleptic characteristics and nutritional value (Pei-Ling et al., 2010). The objective of this review is to provide updated information on the application of emerging technologies in potato starch and its potential to improve functional properties.

\section{STARCH FUNCTIONAL PROPERTIES}

The functional properties of starch can vary depending on the source and the amylose / amylopectin ratio derived from differential expression of genes during the starch biosynthesis (Molavi et al., 2020). The amylose present in starch is responsible for the short-term retrogradation, as well as the viscosity, while the presence of amylopectin is associated with the properties of syneresis and the long-term retrogradation of starch ( 5 days at $4{ }^{\circ} \mathrm{C}$ ) (Tao et al., 2019; Gong et al., 2019; Arp et al., 2020).

Retrogradation of starch is a recrystallization process of the starch that is produced during the cooling stage, when the gelatinized starch (amorphous state) becomes a crystalline structure (Gong et al., 2009). During storage of gelatinized starch, starch molecules lose energy, and hydrogen molecules tend to get stronger. For example, amylose molecules with shorter chains tend to interact faster and stronger with other starch molecules forming a hydrogel network with smaller, thinner and denser cells. The retrogradation of the starch significantly influences the acceptability and the shelf life of the products, as well as on the texture characteristics, greater hardness, greater cohesion and decreased fracture (Karim et al., 2000; Jankowski, 2010).

Throughout refrigerated storage, the tendency of starch to retrograde can be evaluated by the amount of syneresis. This phenomenon is a process in which the water separates from the gel because the starch chains are starting to form a thick structure (Wu et al., 2010). This phenomenon is favorable for products that require freeze-thaw stability such as meat derivatives and vegetarian products that try to emulate them using starch in their formulations due to its swelling and water retention capacity (Solarte-Montúfar et al., 2019) 
The pasting properties of starch depend on the leaching of amylose. The swelling of the granules, the crystallinity and the chain length of the starch components. This property is quantified using a viscosity analyzer (Jin and Xu, 2020). The starch of the tubers and the roots have higher viscosity than the starch of the cereals, because the high temperatures allow the formation of more complex bonds between the amylose in the crystalline region and the amylopectin in the amorphous region, resulting in crystalline structures more strongly and closely bonded crystalline formation. This structure requires high temperatures to absorb water (Takahashi et al., 2005; Marta et al., 2019).

According to Li et al. (2020), the structural changes caused by the elevation in the amylose content inhibits the swelling of the starch granules even at temperatures between $108{ }^{\circ} \mathrm{C}-130{ }^{\circ} \mathrm{C}$, which alters the pasting properties, decreasing the viscosity. On the contrary, amylose is positively linked to water absorption capacity (Yang et al., 2019).

Some studies suggest that the lateral ramifications of amylopectin and the smaller size of the granule, facilitate the absorption of water into the intermolecular spaces, resulting in an increase in solubility, with amylopectin having the highest proportion in the dissolution. The increase in solubility could be attributed to the increase in the amorphous region of starch causing a decrease in the starch crystallinity index (Marta et al., 2019; Ramirez, 2020). The crystallization of the starch leads to an increase in the stiffness of the starch products.

Good quality starches with high starch content and high viscosity of the paste, will have low solubility, high water absorption and high swelling power. High solubility, low water absorption and low swelling power indicate a low quality starch, which when cooled produces thin pastes with little stability when cooled (Hidalgo and Micho, 2016).

\section{EMERGING TECHNOLOGY OF POTATO STARCH MODIFICATION}

The physical modifications of the starch are carried out conventionally by heating and mechanical shearing, however, the process

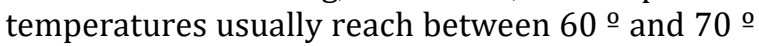
$\mathrm{C}$, causing the loss of molecular organization and consequently, a loss of its crystallinity; in addition, they can be affected by the moisture content of starch during treatment (Bertolini, 2010).

Industrially, the moisture content in starch increases energy consumption during the modification processes, since for drying it is necessary to use centrifuges that allow obtaining between 33-35\% moisture, and are usually expensive. Conventional production of modified starches is expensive for the industrial sector, so innovative techniques that improve the benefit / cost ratio are required (Sriroth et al., 2000).

Emerging technologies are techniques used in the food industry to improve the conditions of processing, preservation and prolonging the shelf life of processed foods without resorting the use of artificial preservatives (Ramos et al., 2013).

In this sense, technologies for high hydrostatic pressure, ultrasound, microwave, electric pulses and ohmic heating are presented as alternatives for the processes of production and innovation of products (Gamboa-Santos et al., 2016).

According to Dolores et al. (2014), high hydrostatic pressure can affect functional properties of starch, it has been shown that pressure-induced gelatinization of starch (150 $\mathrm{MPa}$ ) is very sensitive to changes in temperature, and that viscosity increases in treatments of 100 $200 \mathrm{MPa}\left(20{ }^{\circ} \mathrm{C} / 15 \mathrm{~min}\right)$ and reduces in treatments of $300-400 \mathrm{MPa}\left(20^{\circ} \mathrm{C} / 15 \mathrm{~min}\right)$. These changes are due to the hydrostatic pressure destroying the structure of the starches, favoring the hydration of the amorphous zone of the starch and a distortion of the crystalline region. In hydrostatically pressurized starch, there is little amylose leaching, however, the surface of the granule changes from smooth to rough, probably due to the presence of amylopectin. In gelatinized starch, high hydrostatic pressure decreases enzyme digestibility, causing immediate starch retrogradation. (Pei-Ling et al., 2010)

In the year 2019, Larrea et al. (2019) studied the effect of high hydrostatic pressure (HHP) on the functional properties of potato starch. The native starch was mixed with different proportions of water, forming suspensions of $10 \%$ (w / w), $20 \%$ $(\mathrm{w} / \mathrm{w})$ and $30 \%(\mathrm{w} / \mathrm{w})$, and then placed in a flexible packaging and subjected to process hydrostatic at $600 \mathrm{MPa} / 25{ }^{\circ} \mathrm{C} / 15 \mathrm{~min}$. At the end of the process, the samples were stored at $25^{\circ}$ $\mathrm{C}$ until analysis. The results showed that the $20 \%$ $(\mathrm{w} / \mathrm{w})$ suspension had a greater swelling power value, $22.8 \%$, unlike the $10 \%(17.7 \%)$ and $30 \%$ (11.4\%) suspensions. The gelatinization was 
measured by percentage of gel formation according to the Blaszczak et al. (2007), resulting in $18.5 \%$ in $10 \%$ suspensions, slightly higher than those obtained in 20\% (p>0.05) and 30\% (p> $0.05)$ suspensions. The study showed that high hydrostatic pressure allows producing modified starches in economically viable conditions, with times and processing significantly less than those used by conventional methods.

In another study by Colussi et al. (2017), they evaluated the effect of high hydrostatic pressure on potato starch on its functional properties. aqueous suspension of 1:3 ratio of starch to water were made and placed in flexible packaging. The processing was at $400 \mathrm{MPa}$ and $600 \mathrm{MPa}$ for 3 and 6 cycles of $10 \mathrm{~min}$ each at a temperature of $21^{\circ} \mathrm{C}$. The processed sample was centrifuged at $3000 \mathrm{xg}$ for $15 \mathrm{~min}$ and dried at $40{ }^{\circ} \mathrm{C}$ for $24 \mathrm{~h}$. The samples treated at $400 \mathrm{MPa}$ for 3 cycles had higher viscosities than the unprocessed sample ( $p$ $<0.05$ ).

The sample treated at $600 \mathrm{MPa}$ for 6 cycles showed a higher gelatinization temperature $(\mathrm{p}$ $<0.05)$. In the scanning electron micrograph analysis, it was observed that the starches processed at $400 \mathrm{MPa}$ and a number of cycles greater than 6 presented irregular surfaces without destruction of the granules, unlike the native potato starch that presented a smooth surface. The authors concluded that the application of HHP combined with the increase in the number of cycles, improves the viscosity of the starch paste and promotes changes in morphology causing positive effects on functional properties.

A the same as the high hydrostatic pressure, microwaves cause structural changes in the starch. The main effect is the dielectric heating that occurs when starch and microwaves interact. This heating causes the breaking of hydrogen bonds and the reorientation of the dipoles in the sample. Microwaved starch increases its gelatinization temperature and significantly decreases its viscosity, however, the swelling power is not affected in starches with a greater presence of amylopectin than amylose, because the latter is less resistant to heating (Lewicka et al., 2015).

Przetaczek et al. (2019), evaluated the effect of microwave radiation on the functional properties of potato starch enriched with minerals. The samples of native starch were placed in a 2450 $\mathrm{MHz}$ microwave and irradiated at $440 \mathrm{~W}$ and 800 $\mathrm{W}$, then mixed with mineral additives to increase their nutritional value. Microwave modified starch at $440 \mathrm{~W}$ and $800 \mathrm{~W}$ had similar values of amylose content ( $p>0.05)$, but different gelatinization temperature values of $59.6{ }^{\circ} \mathrm{C}$ and $56.7{ }^{\circ} \mathrm{C}(\mathrm{p}$ $<0.05)$, respectively. The viscosity values of the sample treated at $440 \mathrm{~W}$ were significantly higher by $27 \%$ than the samples treated at $600 \mathrm{~W}$. Consequently, irradiation is a physical method that allows obtaining starches with functional quality to form a viscous paste that improves texture of food products, in addition to allowing its enrichment with minerals such as potassium, magnesium and iron.

Cao et al. (2019), applied two emerging technologies to evaluate the effect they have on the physicochemical properties of potato starch. The samples were suspensions of starch: water 1: 1.7 (w / v), which were subjected to microwave irradiation (unknown parameters) for a time of 2 min and ultrasound at $50 \mathrm{~W}$ for $10 \mathrm{~min}$ with 25 second intervals. The microwave treatment presented a starch with a higher gelatinization temperature $67.26{ }^{\circ} \mathrm{C}$, while the ultrasound treatment had a higher viscosity $(p<0.05)$ and reduced syneresis $(p<0.05)$, similar to the conventional dry heat process at $120^{\circ} \mathrm{C} / 3 \mathrm{~h}$. The results suggest that ultrasonic treatments can improve the freezing and thawing stability of potato starch and lead to a weak retrogradation tendency, which is favorable for industrialized foods.

According to Monroy et al. (2018), during ultrasound, acoustic cavitation causes the implosive growth and collapse of microbubbles present in the treated sample. This collapse generates heat (up to $5000 \mathrm{~K}$ ) and pressure (up to $20 \mathrm{MPa}$ ) in a short time. In the starch, nearby microbubbles to polymer chains that collapse lead to the breaking of macromolecular bonds and the formation of long chain radicals.

Zhang et al. (2019) studied the rheological characteristics of potato starch after being subjected to ultrasound. Starch at $99.5 \%$ purity, was purchased commercially containing 14.4\% moisture. The starch-water suspensions were prepared at $2.0 \%$ and subjected to different ultrasonic intensities, $75 \mathrm{~W} / \mathrm{cm}^{2}, 150 \mathrm{~W} / \mathrm{cm}^{2}$, $225 \mathrm{~W} / \mathrm{cm}^{2}$ or $300 \mathrm{~W} / \mathrm{cm}^{2}$, all at $25{ }^{\circ} \mathrm{C}$. According to rheological analyzes, the relationship between shear and cutting speed, show that starch pastes with different treatments correspond to Newtonian and non-Newtonian fluids. The shear stress of the native starch was $24.21 \mathrm{~Pa}$, while the modified starch presented tensions of $18.82 \mathrm{~Pa}$, $12.56 \mathrm{~Pa}$ and $8.86 \mathrm{~Pa}$, when the intensity of the ultrasonic sound was $300 \mathrm{~W} / \mathrm{cm}^{2}$ and the times in the ultrasonic field were $0,5 \mathrm{~min}, 1 \mathrm{~min}$ and 5 min, respectively. The authors concluded that shear stress and apparent viscosity decrease with 
increasing ultrasonic time, in addition, the properties evaluated were positively correlated, indicating that the intensity of ultrasonic sound and time have positive effects on potato starch.

Nie et al. (2017), evaluated the effect of the ultrasound process on the functional properties of potato starch. The starch was purchased commercially with $99.7 \%$ purity. Different suspensions were prepared, $0.05 \%$ to $1 \%$ (w / v), and was treated with ultrasound in an ice-water bath at different intensities $(0,75,150$ and $225 \mathrm{~W}$ $\mathrm{cm}-2$ ) for $5 \mathrm{~min}$. It was observed that in the sample treated at $75 \mathrm{~W} / \mathrm{cm}^{2}$ retrogradation did not occur, which differs from the studies carried out by Zuo et al. (2009) and Yu et al. (2013) that mention that the effect of cavitation produced by ultrasound has not significant effects on retrogradation of starch. This difference may be explained, due to the fact that potato starch contains long amylose chains which due to its degree of polymerization and the interaction of hydrogen bonds result in reduced retrogradation. Texture analyzes showed that the hardness decreased significantly when the time and ultrasonic intensity is increased, this indicates that softer starch gels can be produced by the ultrasonic treatment. Given this, the application of emerging technologies in the production of modified starches increases in greater intensity of the functional properties of native starches. However, it is worth noting that the pressures applied can vary according to the potato species and each case requires an exhaustive study.

Another emerging technology is the electric pulse fields, which cause permeabilization in the material through a process known as electroporation. The treated starch receives short duration, high voltage pulses between two electrodes. The starch granules treated with electric pulses $(50 \mathrm{kV} / \mathrm{cm})$ present roughness on the surface, presence of aggregates, decrease in gelatinization temperature and reduction of the degree of crystallinity and viscosity (Maniglia et al., 2020) For example, potato starch granules tend to contain more water molecules within crystalline cells, contributing to increased electrical conductivity and changes in starch properties induced by electricity fields (Zhu, 2018).

Chen et al. (2020), studied the effect of electric pulse fields on esterified potato starch. The starch was esterified with octenyl succinic anhydride and subjected to electrical pulses. The intensity of the field varied in $0,2,3,4,5$ and $6 \mathrm{kV} / \mathrm{cm}$. and processing time was 50 minutes. The viscosity of the starches was indirectly proportional to the intensity of the pulsed electric field. The esterified potato starch treated at $4 \mathrm{kV} / \mathrm{cm}$, showed lower swelling power of the granules and decreased viscosity, which reflects the thermal stability of the paste. Pulsed electric field greater than $6 \mathrm{kV} /$ $\mathrm{cm}$ did not cause substantial changes in viscosity. The esterified starch treated by an electric pulse field, caused structural alterations of the starch, such as the breakdown of granules and decrease of the molecular order, favoring the pasting properties, applicable to the paper, textile and food industry.

Finally, it should be mentioned that modified starch studies by emerging technologies were carried out on a pilot scale but could have commercial effects, including the advantage of using green technologies for food processing. From a development perspective, industries must improve the efficiency of their production processes, as well as their environmental performance, in addition, the demand of demanding markets increases the versatility of starch modification methods. It is suggested to investigate new emerging technologies in the modification of potato starch, that contribute to the creation of new opportunities, that it adapts to the needs of society and that seeks to mitigate the degradation of the environment.

\section{CONCLUSION}

Through this review, the potential of emerging technologies in the modification of the potato starch. The investigations carried out demonstrate that emerging technologies such as high hydrostatic pressure, ultrasound and microwaves, positively affect some rheological, technological and functional characteristics, such as solubility, swelling power, retrogradation and water absorption capacity of the starch. Characterizations made from modified potato starch show that unconventional techniques produce minimal structural changes, which satisfy aspects of availability and versatility for their wide application in industry.

Studies of starches modified by emerging technologies have increased over the years, these technologies seek to be applicable for the development of new products. However, there are still more emerging technologies to research such as high pressure homogenization, cold plasma, electric pulse, among others. 


\section{REFERENCES}

Arp, C., Correa, M. and Ferrero, C. (2020). Kinetic study of staling in breads with high-amylose resistant starch, Food hydrocolloids. 106, 105-879.

Bello-Pérez, L., Contreras, S., Romero, R., Solorza, J. and Jiménez, A. (2002). Chemical and functional properties of modified banana starch (variety Macho). Agrociencia, 36(2), 169-180.

Bertolini, A. (2010). Starches: characterization, properties and Applications. CRC Press, Boca Raton, FL, pp 276

Blaszczak, W., Fornal, J., Kiseleva, V., Yuryev, V.P., Sergeev, A.I. and Sadowska, J. (2007). Effect of high pressure on thermal, structural and osmotic properties of waxy maize and Hylon VII starch blends. Carbohydrate Polymers. 68, 387-396.

Cao, M. and Gao, Q. (2020). Effect of dual modification with ultrasonic and electric field on potato starch. International Journal of Biological Macromolecules. 150, 637-643.

Colussi, R., Kaur, L., Da Rosa, E., Guerra, A., Stewart, R. and Singh, J. (2018). High pressure processing and retrogradation of potato starch: Influence on functional properties and gastro-small intestinal digestion in vitro. Food Hydrocolloids. 75, 131-137.

Chen, B., Wen, Q., Zeng, X., Abdul, R., Roobab, U. and $\mathrm{Xu}, \mathrm{F}$. (2020). Pulsed electric field assisted modification of octenyl succinylated potato starch and its influence on pasting properties. Carbohydrate Polymers. 254, 117-294.

De León, C. (2015). Caracterización y comportamiento físico químico del almidón de la achira (Canna edulis ker) con relación al almidón de yuca (Manihot esculenta crantz) (Tesis de pregrado). Universidad de Guayaquil, Guayaquil, Ecuador.

Dolores-Álvarez, M., Fuentes, R., Dolores, M. and Canet, W. (2014). Effects 1 of high hydrostatic pressure on rheological and thermal properties of chickpea (Cicer arietinum L.) flour slurry and heat-induced paste. Innovative Food Science \& Emerging Technologies. 21, 12-23.

Dupuis, J. and Liu, Q. (2019). Potato Starch: A Review of Physicochemical, Functional and
Nutritional Properties. American journal of potato research. 96(2), 127-138.

Gamboa-Santos, J., Rodríguez, J., Carvajal, G. and Pilamala, A. (2016). Aplicación de tecnologías emergentes al procesamiento de frutas con elevada calidad nutricional: Revisión. Revista Colombiana de Investigaciones Agroindustriales. 3, 57-75.

Goel, C., Semwal, A.D., Khan, A., Kumar, S. and Kumar, S. (2020). Physical modification of starch: changes in glycemic index, starch fractions, physicochemical and functional properties of heat-moisture treated buckwheat starch. Journal of Food Science and Technology. 57, 2941-2948.

Gong, B., Cheng, L., Gilbert, R. and Li, C. (2019). Distribution of short to medium amylose chains are major controllers of in vitro digestion of retrograded rice starch, Food Hydrocolloids. 96, 634-643.

Hidalgo, A. and Micho, N. (2016). Modificación química de almidón nativo de Maca (Lepidium Peruvianum) en sus características fisicoquímicas y reológicas (Tesis de pregrado). Universidad Nacional del Centro del Perú, Junín, Perú.

Jankowski, T. (2010). Influence of starch retrogradation on the texture of cooked potato tuber. International Journal of Food Science and Technology. 27(6), 637-642.

Jin, Q. and Xu, X. (2020). Microstructure, gelatinization and pasting properties of rice starch under acid and heat treatments. International Journal of Biological Macromolecules. 149, 1098-1108.

Karim, A. A., Norziah, M. H. and Seow, C. C. (2000). Methods for the study of starch retrogradation. Food Chemistry. 71(1), 936.

Larrea, D., Tabilo, G. and Ferrari, G. (2019). Potato Starch Hydrogels Produced by High Hydrostatic Pressure (HHP): A First Approach. Polymers Journal. 11(1673), 1-18.

Lewicka, K., Przemyslaw, S. and Kurcok, P. (2015). Chemical Modifications of Starch: Microwave Effect. International Journal of Polymer Science. 1-10.

Li, C., Dhital, S., Gilbert, R. G. and Gidley, M. J. (2020). High-amylose wheat starch: 
structural basis for water absorption and pasting properties. Carbohydrate Polymers. $245,116-557$.

Maniglia, B. C., Castanha, N., Le-Bail, P., Le-Bail, A. and Augusto, P. E. D. (2020). Starch modification through environmentally friendly alternatives: a review. Critical Reviews in Food Science and Nutrition. 124.

Marta, H., Cahyana, Y., Arifin, H. R. and Khairani, L. Comparing the effect of four different thermal modifications on physicochemical and pasting properties of breadfruit (Artocarpus altilis) starch. International Food Research Journal. 26(1), 269-276.

Molavi, H., Behfar, S., Shariati, M., Kaviani, M. and Atarod, S. (2015). A review on biodegradable starch based film. Journal of Microbiology, Biotechnology and Food Science. 4(5), 456-461.

Mollega, S., Barrios, S., Feijoo, J., Contreras, J., MÜller, A. and López, F. (2011). Modificación química de almidón de yuca nativo mediante la reacción de carboximetilación en medio acuoso. Revista de la Facultad de Ingeniería Universidad Central de Venezuela, 26(1), 117-128.

Monroy, Y., Rivero, S. and García, M. (2018). Microstructural and techno-functional properties of cassava starch modified. Ultrasonics -Sonochemistry. 42, 795-804.

Nie, H., Li, Ch., Liu, P., Lei, C. and Li, J. (2017). Retrogradation, gel texture properties, intrinsic viscosity and degradation mechanism of potato starch paste under ultrasonic irradiation, Food Hydrocolloids. 95, 590-600.

Nurulain, S., Yazid, N., Norhayati M. and Matias, H. (2018). Application of Starch and StarchBased Products in Food Industry. Journal of Science and Technology. 10(2), 144-174.

Pei-Ling, L., Xiao-Song, H. and Shen, Q. (2010). Effect of high hydrostatic pressure on starches: A review. Starch -Stärke. 62(12), 615-628.

Perez, S. and Bertoft, E. (2010). The molecular structures of starch components and their contribution to the architecture of starch granules: A comprehensive review. Starch biosynthesis nutrition biomedical. 62(8), 389-420.
Przetaczek, I., Fortuna, T., Wodniak, M., Labanowska, M., Pajal, P. and Krolikowska, K. (2019). Properties of potato starch treated with microwave radiation and enriched with mineral additives. International Journal of Biological Macromolecules. 124, 229-234.

Ramírez, G. (2020). Extracción con ultrasonido y su efecto sobre las propiedades funcionales y estructurales del almidón de frutos de guanábana (Annona muricata L.). (Disertación de Maestría). Universidad Autónoma de Nayarit, Nayarit, México.

Ramos, M., Romero, C. and Baustista, S. (2018). Modified starch: properties and uses as edible coatings for the preservation of fresh fruits and vegetables. Revista Iberoamericana de Tecnología Post cosecha. 19(1), 1-9.

Ramos, B., Miller, F., Brandao, T., Teixeira, P. and Silva, C. (2013). Fresh fruits and vegetablesAn overview on applied methodologies to improve its quality and safety. Innovative Food Science and Emerging Technologies. 20, 1-15.

Raventós, M. (2005). Industria de alimentos tecnologias emergentes. Edicions UPC, Barcelona, España, pp. 25-127.

Schmiele, M., Sampaio, U., Goecking, P. and Silva, M.T. (2019). Physical Modifications of Starch. Starches for Food Application Chemical, Technological and Health Properties, Academic Press, Cambridge, USA, pp. 223-269.

Solarte-Montúfar, J., Díaz-Murangal, A, OsorioMora, O. and Mejía-España, D. (2019). Propiedades Reológicas y Funcionales del Almidón. Procedente de Tres Variedades de Papa Criolla. Información tecnológica. 30(6), 35-44.

Sritoth, K., Piyachomkwan, K., Wanlapatit, S. and Oates, C. 2000. Cassava Starch Technology: The Thai Experience. Starch- Stärke. 52, 439-449.

Takahashi, T., Miura, M., Ohisa, N. and Kobayashi, S. (2005). Modification of gelatinization properties of rice flour by heat-treatment. Journal of the Society of Rheology. 33(2), 8185. 
Tao, K., Li, C., Yu, W., Gilbert, R. and Li, E. (2019). How amylose molecular fine structure of rice starch affects functional properties, Carbohydrate Polymers. 204, 24-31.

Wu, Y., Chen, Z., Li, X., and Wang, Z. (2010). Retrogradation properties of high amylose rice flour and rice starch by physical modification. Food Science and Technology. 43(3), 492-497.

Yang, Y., Wang, L., Li, Y., Qian, H. F., Zhang, H., Cheng Wu, G. and Qi, X. G. (2019). Investigation the molecular degradation, starch-lipid complexes formation and pasting properties of wheat starch in instant noodles during deep-frying treatment. Food Chemistry. 283, 287-293.

Yu, S., Zhang, Y., Ge, Y., Zhang, Y., Sun, T., Jiao, Y. and Zheng, X.-Q. (2013). Effects of
Ultrasound Processing on the Thermal and Retrogradation Properties of Non waxy Rice Starch. Journal of Food Process Engineering. 36(6), 793-802.

Zhang, Y., Li, J., Zhang, Z., Wei, Q. and Fang, K. (2019). Rheological law of change and conformation of potato starch paste in an ultrasound field. Journal of Food Measurement and Characterization. 13, 1695-1704.

Zhu, F. (2018). Modifications of starch by electric field based techniques. Trends in Food Science \& Technology. 75, 158-169.

Zuo, J.Y., Knoerzer, K., Mawson, R., Kentish, S. and Ashokkumar, M. (2009). The pasting properties of sonicated waxy rice starch suspensions. Ultrasonics Sonochemistry. 16, 462-468. 